\title{
Electrical properties of pulsed UV laser irradiated amorphous carbon
}

\author{
Y. Miyajima, ${ }^{\text {a) }}$ A. A. D. T. Adikaari, S. J. Henley, J. M. Shannon, and S. R. P. Silva ${ }^{\text {b) }}$ \\ Nano-Electronic Centre, Advanced Technology Institute, University of Surrey, Guildford, Surrey GU2 7XH, \\ United Kingdom
}

(Received 6 February 2008; accepted 20 March 2008; published online 15 April 2008)

\begin{abstract}
Amorphous carbon films containing no hydrogen were irradiated with a pulsed UV laser in vacuum. Raman spectroscopy indicates an increase in the quantity of $s p^{2}$ clustering with the highest laser energy density and a commensurate reduction in resistivity. The reduction of resistivity is explained to be associated with thermally induced graphitization of amorphous carbon films. The high field transport is consistent with a Poole-Frenkel type transport mechanism via neutral trapping centers related to $s p^{2}$ sites which are activated under high fields. Decreasing the resistivity is an important feature for use of carbon as an electronic material. (C) 2008 American Institute of Physics. [DOI: $10.1063 / 1.2908208$ ]
\end{abstract}

Amorphous carbon $(a-\mathrm{C})$ is a unique material as it consists of differently hybridized atoms: sp, $s p^{2}$ and $s p^{3}$. One of the remarkable properties of $a$-C is its smooth surface. ${ }^{1}$ Furthermore, depending on the composition, it is possible to deposit $a-\mathrm{C}$ films having different properties. From the electrical properties point of view, the $s p^{3}$ fraction and the $s p^{2}$ clustering are two key considerations that dictate the density of states in the films. ${ }^{2,3}$ Potential electronic devices based on $a$-C grown by pulsed laser deposition (PLD) have been recently reported. ${ }^{4}$ In addition to PLD, there are a variety of deposition methods for $a$-C such as magnetron sputtering, ${ }^{5}$ plasma enhanced vapor deposition, ${ }^{6}$ filtered cathodic vacuum arc, ${ }^{7}$ and mass selected ion beams deposition. ${ }^{8}$ The $a-\mathrm{C}$ has been used in several applications that mainly exploit its mechanical properties such as a protective layer for hard disk drives where films with a high $s p^{3}$ fraction have high hardness, ${ }^{9}$ a smooth surface, ${ }^{10}$ and low friction. ${ }^{11}$

Thermal annealing is a common technique to improve the electrical properties of materials and contacts. The effect on tetrahedral $a-\mathrm{C}$ is to induced graphitization from $s p^{3}$ to $s p^{2}$, increase the amount of $s p^{2}$ clustering, and reduce the stress in the films. ${ }^{12}$ Pulsed UV laser annealing has been used to crystallize hydrogenated amorphous silicon. ${ }^{13-15}$ The merit of pulsed laser annealing (PLA) with UV photons is that the laser is absorbed close to the surface and the effect to the substrate is minimal compared to thermal annealing in a furnace.

PLA at visible and infrared wavelengths of $a-\mathrm{C}: \mathrm{H}$ deposited by plasma-enhanced chemical-vapor deposition has been reported and ablation of the films has been observed. ${ }^{13}$ In this study, we report the effects of PLA with UV laser on nonhydrogenated $a$-C films. The $a$-C films were deposited using PLD on highly doped $c$-Si substrates in vacuum at a base pressure of $10^{-6}$ Torr. Prior to deposition, substrates were cleaned using solvents, then rinsed with de-ionized water and blow dried using $\mathrm{N}_{2}$.

A KrF Lambda Physik excimer laser (LPX 210i), operating at $248 \mathrm{~nm}$ with $25 \mathrm{~ns}$ full width at half maximum pulse duration was used as the laser source for PLD. The highly oriented pyrolytic graphite target (Kurt J. Lesker, 99.999\% pure) was rotated during deposition to avoid ablation from the same spot. The surface of the target was cleaned using

\footnotetext{
${ }^{a)}$ Electronic mail: y.miyajima@ @urrey.ac.uk.

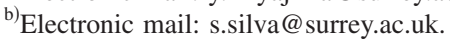

laser ablation before deposition with an energy density of $12 \mathrm{~J} / \mathrm{cm}^{2}$. For film deposition, an energy density of $4 \mathrm{~J} / \mathrm{cm}^{2}$ was used at $10 \mathrm{~Hz}$. The substrates were placed $6 \mathrm{~cm}$ away from the graphite target, and $80 \mathrm{~nm}$ thick $a$-C films were deposited with a growth rate of $8.5 \mathrm{~nm} / \mathrm{min}$.

PLA of deposited samples was performed with the same laser in a stainless steel vacuum chamber with a quartz window, mounted on an automated translation stage. An 8 $\times 3 \mathrm{~mm}^{2}$ asymmetric pulse ${ }^{15}$ was scanned along the film at $2 \mathrm{~mm} / \mathrm{s}$ at $20 \mathrm{~Hz}$ repetition rate. Energy densities of 30, 60, 90 , and $120 \mathrm{~mJ} / \mathrm{cm}^{2}$ were used at a base pressure of 3 $\times 10^{-4}$ Torr.

A Renishaw 2000 Raman microscope with two types of excitation laser, $\mathrm{Ar}^{+}(514.5 \mathrm{~nm})$ and semiconductor $(782 \mathrm{~nm})$ lasers, were used for the visible Raman spectroscopy. The Raman spectra were fitted using a Breit-WignerFano line shape to the $G$ peak and Lorentzian line shape to the $D$ peak. $^{16,17}$ The peak positions are around 1600 and $1350 \mathrm{~cm}^{-1}$, respectively. The Lorentzian line shape is recovered in the limit of $1 / Q \rightarrow 0$. The corrected $G$ peak position $\omega_{\max }$ (Ref. 16) is used as a $G$ peak position in this study. The $D$ and $G$ peaks are attributed to the breathing mode of the sixfold aromatic rings and all $s p^{2}$ sites, respectively. Therefore, the intensity ratio of the $D$ and the $G$ peaks, $I(D) / I(G)$, indicates the degree of $s p^{2}$ clustering in $a-\mathrm{C}$ films. ${ }^{16}$

Figure 1 shows the Raman spectra of laser annealed $a$-C films. Significant changes are not observed with increasing laser energy below $90 \mathrm{~mJ} / \mathrm{cm}^{2}$. However, the $D$ peak intensity increases after $120 \mathrm{~mJ} / \mathrm{cm}^{2}$ PLA compared with the other samples at both excitation wavelengths. Figure 2 shows the increase of the $G$ peak position and $I(D) / I(G)$ for sample irradiated at $120 \mathrm{~mJ} / \mathrm{cm}^{2}$, which indicates $s p^{2}$ clustering. The increase of the $G$ peak position and the decreases of the $I(D) / I(G)$ with decreasing wavelength of the exciting laser also has been reported elsewhere. ${ }^{18}$ Raman spectra with both excitation wavelengths give a trend similar to that found after thermal annealing. ${ }^{12}$

Longer excitation wavelengths excite larger clusters with lower bandgap and lower frequency breathing modes. ${ }^{18}$ Figure 2 shows that the larger excitation wavelength shows larger $I(D) / I(G)$, therefore it indicates the presence of clusters even in as deposited films. It is possible to estimate the cluster size based on these measurements. ${ }^{18}$ Before laser annealing, PLD $a$-C films seem to be ta-C (Ref. 19) and sig- 


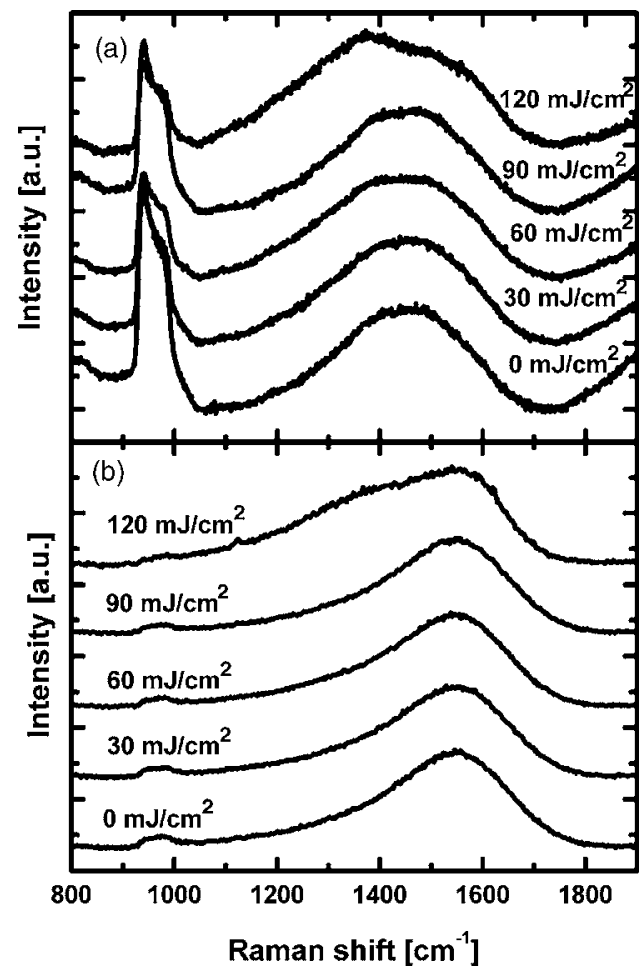

FIG. 1. The visible Raman for laser annealed $a$-C with (a) $514.5 \mathrm{~nm}$ and (b) $782 \mathrm{~nm}$ lasers.

nificant clustering is thought to not occur. The cluster size is estimated to be about $1 \mathrm{~nm}$ for as deposited $a-\mathrm{C}$ and laser annealed films with the laser energy density between $30-90 \mathrm{~mJ} / \mathrm{cm}^{2}$. For the laser annealed sample at $120 \mathrm{~mJ} / \mathrm{cm}^{2}$, the cluster size increases to around $10 \mathrm{~nm}$. The $s p^{2}$ clustering in $a$-C films is apparent from Raman spectra.

Electrical characterization of the films was carried out using sandwich structures. A highly doped $c$-Si wafer with a dc sputtered $100 \mathrm{~nm}$ thick aluminium on the back was used

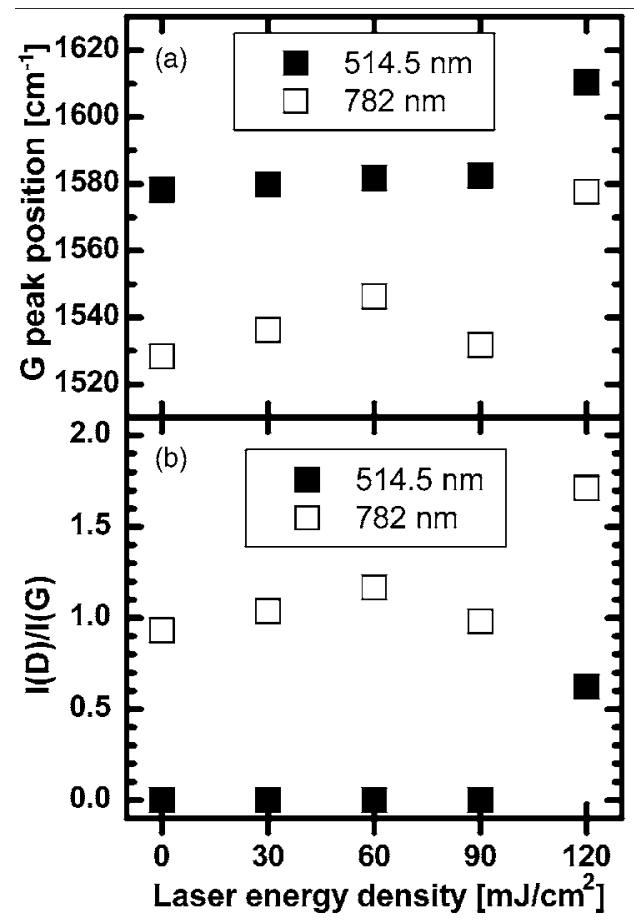

FIG. 2. (a) The $G$ peak position and (b) $I(D) / I(G)$ of Raman spectra at

514.5 and $782 \mathrm{~nm}$ excitation lasers against laser energy density. Slightly increases at $120 \mathrm{~mJ} / \mathrm{cm}^{2}$, as shown in Figure $3(\mathrm{c})$.
Downloaded 30 Mar 2009 to 131.227.178.132. Redistribution subject to AlP license or copyright; see http://apl.aip.org/apl/copyright.jsp
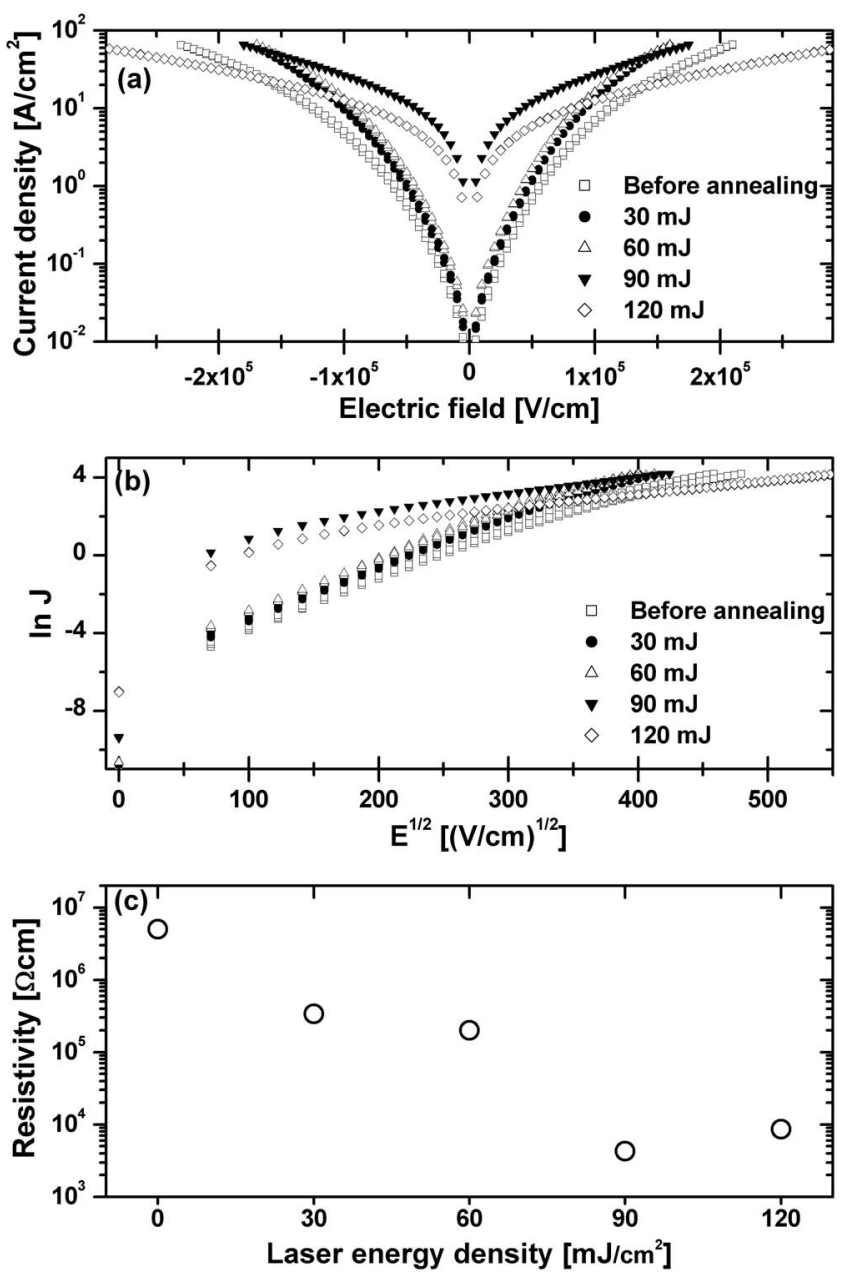

FIG. 3. (a) $J-E$ characteristics, (b) Poole-Frenkel plot, and (c) resistivity at low electric fields.

for the bottom contact. A circular top electrode with an area of $1.5 \times 10^{-4} \mathrm{~cm}^{2}$ was fabricated by dc sputtering $50 \mathrm{~nm}$ thick $\mathrm{Cr}$ through a shadow mask. The $a$-C films were $80 \mathrm{~nm}$ thick. Electrical measurements were carried out using a Keithley 236 sourcemeter at room temperature.

The current density versus electric field $(J-E)$ characteristics of the films is shown in Figure 3(a). The conduction mechanism of $a$-C films is different between the low and the high electric fields $\left(>10^{4} \mathrm{~V} / \mathrm{cm}\right)$. The $J-E$ curves are symmetric, which implies the conduction mechanism is bulk limited, rather than contact limited since two different electrodes (highly doped $c$-Si for the bottom and $\mathrm{Cr}$ for the top) were used. The most probable conduction mechanism at high fields is Poole-Frenkel conduction via neutral trapping centers. In such a case, the log of the current density is proportional to the square root of the electric field at high fields for this situation. ${ }^{19}$

Figure 3(b) shows that indeed there is a linear relationship between $\ln J$ and $E^{1 / 2}$ at high fields. Pool-Frenkel conduction seems to occur in the as deposited sample and laser annealed sample with the laser energy density between $30-60 \mathrm{~mJ} / \mathrm{cm}^{2}$. The samples laser annealed of 90 and $120 \mathrm{~mJ} / \mathrm{cm}^{2}$ seem to be Ohmic. The reason of Ohmic conduction might be the creation of filamentlike paths consisting of $s p^{2}$ hybridization at $90 \mathrm{~mJ} / \mathrm{cm}^{2}$.

The resistivity obtained from the low electric field region decreases with increasing laser energy to $90 \mathrm{~mJ} / \mathrm{cm}^{2}$, then slightly increases at $120 \mathrm{~mJ} / \mathrm{cm}^{2}$, as shown in Figure 3(c). AlP license or copyright; see http://apl.aip.org/apl/copyright.jsp 


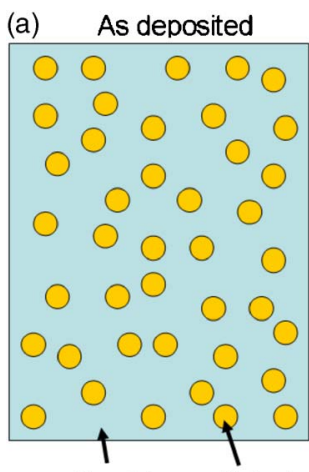

$\mathrm{sp}^{3}$ matrix $\mathrm{sp} \mathrm{p}^{2}$ cluster

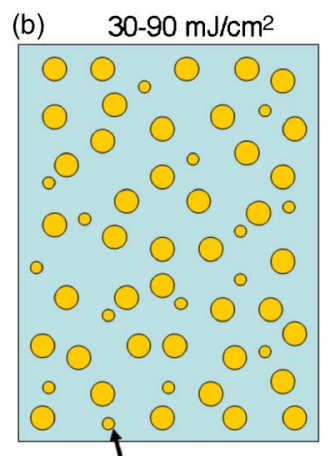

$\mathrm{sp}^{3}$ to isolated $\mathrm{sp}^{2}$ transition

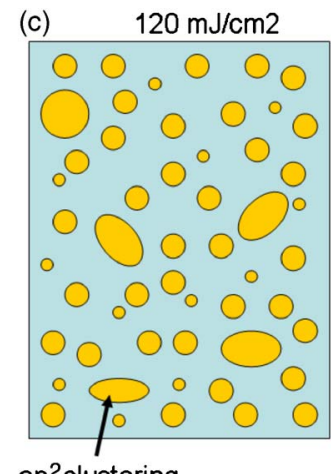

$\mathrm{sp} \mathrm{p}^{2}$ clustering
FIG. 4. (Color online) A schematic diagram of $a-\mathrm{C}$ films based on the cluster model and results of Raman spectroscopy: (a) as deposited $a-\mathrm{C}$, (b) laser annealed $a-\mathrm{C}$ with the laser energy density of $30-90 \mathrm{~mJ} / \mathrm{cm}^{2}$, and (c) laser annealed $a-C$ with the laser energy density of $120 \mathrm{~mJ} / \mathrm{cm}^{2}$.
The decrease of the resistivity can be attributed to the transformation from $s p^{3}$ to isolated $s p^{2}$ hybridization similar to normal annealing since $I(D) / I(G)$ does not change. ${ }^{12}$ However, the increase of the resistivity at $120 \mathrm{~mJ} / \mathrm{cm}^{2}$ contradicts the Raman data $I(D) / I(G)$ since the $s p^{2}$ clustering should decrease the resistivity compared with $90 \mathrm{~mJ} / \mathrm{cm}^{2}$.

Figure 4(a) shows that the as deposited $a$-C films have small $s p^{2}$ clusters embedded in the $s p^{3}$ matrix. Figure 4(b) shows the laser annealed $a-\mathrm{C}$ films with the laser energy density between $30-90 \mathrm{~mJ} / \mathrm{cm}^{2}$ with an increase in the number of isolated $s p^{2}$ hybridizations. Figure 4(c) shows that the size of the $s p^{2}$ clusters has increased following annealing with the laser energy density of $120 \mathrm{~mJ} / \mathrm{cm}^{2}$. Isolated $s p^{2}$ sites, formed during laser annealing between 30 and $90 \mathrm{~mJ} / \mathrm{cm}^{2}$, are thought to be the hopping centers at low electric fields and the neutral trapping centers responsible for conduction at high electric fields.

A decrease of the resistivity with increasing laser energy $\left(30-90 \mathrm{~mJ} / \mathrm{cm}^{2}\right)$ can be explained by the increase of the density of the hopping sites ( $s p^{2}$ clusters), but the size of the $s p^{2}$ clusters is estimated to be small $(1 \mathrm{~nm})$ according to the $I(D) / I(G)$ of Raman. The slight increase of the resistivity from 90 to $120 \mathrm{~mJ} / \mathrm{cm}^{2}$, could be attributed to a decrease in the thickness. When $s p^{2}$ clustering occurs, the volume of the films might decrease as a result of the microstructural changes as has been previously observed for $a-\mathrm{C}: \mathrm{H}^{20}{ }^{20} \mathrm{How}-$ ever, in the hydrogen free $a-\mathrm{C}$ case, laser ablation of the film is thought to occur at the higher laser energy densities.

A Digital Instruments, Dimension 3100 atomic force microscope (AFM) was used to analyze the surface topography in the tapping mode. The rms roughness of the surface was estimated from AFM data. From the AFM analysis, it was estimated that the rms surface roughness was $<0.3 \mathrm{~nm}$ for both as deposited and laser irradiated films including those annealed at $120 \mathrm{~mJ} / \mathrm{cm}^{2}$.

This observation suggests that the UV-PLA process with a laser energy density below $120 \mathrm{~mJ} / \mathrm{cm}^{2}$ does not modify the surface roughness. The visible and infrared lasers ablate or spallate the surface of $a-\mathrm{C}: \mathrm{H}$ films and glassy carbon when the laser energy density is of the order of sub-J/ $\mathrm{cm}^{2}$. These surface were reported to be smooth. ${ }^{20}$ It is thought that the $120 \mathrm{~mJ} / \mathrm{cm}^{2}$ laser could induce similar phenomenon on hydrogen free $a$-C films resulting in thinning of the films while retaining a smooth surface. Furthermore, the laser was scanned on the surface of the films, so, the bell-like crater did not appear on the surface of the films after laser irradiation. Thus, homogeneous thickness reduction could occur since the surface of $a$-C tends to be naturally smooth. ${ }^{1}$
In conclusion, UV-PLA was carried out on nonhydrogenated $a$-C films. The resistivity of the films decreases with increasing laser energy density, without changing the surface roughness. The reduction in resistivity is explained by thermally induced localized graphitization of films. The transition from $s p^{3}$ to isolated $s p^{2}$ hybridization explains the reduction in resistivity of the film. The improvement in the conductivity by PLD while maintaining the surface smoothness is a useful technique for the fabricating $a$-C thin film devices such as resonant tunneling diodes ${ }^{4}$ that require accurate thickness control of the layers with smooth surfaces.

The authors are grateful to the EPSRC Swindon UK for funding this program via a Portfolio Partnership award. The authors would like to thank to Dr. J.D. Carey for the discussion on Raman spectroscopy on $a$-C.

${ }^{1}$ M. Moseler, P. Gumbsch, C. Casiraghi, A. C. Ferrari, and J. Robertson, Science 309, 1545 (2005).

${ }^{2}$ Amorphous carbon: State of the Art, edited by S. R. P. Silva, J. Robertson, W. I. Milne, and G. A. J. Amaratunga (World Scientific, Singapore, 1997). ${ }^{3}$ Properties of Amorphous Carbon, edited by S. R. P. Silva (INSPEC IEE, London, 2003).

${ }^{4}$ S. Bhattacharyya, S. J. Henley, E. Mendoza, L. Gomez-Rojas, J. Allam, and S. R. P. Silva, Nat. Mater. 5, 19 (2006).

${ }^{5}$ J. Schwan, S. Ulrich, T. Theel, H. Roth, H. Ehrhardt, P. Becker, and S. R. P. Silva, J. Appl. Phys. 82, 6024 (1997).

${ }^{6}$ S. R. P. Silva and G. A. J. Amaratunga, Thin Solid Films 253, 146 (1994). ${ }^{7}$ G. A. J. Amaratunga, V. S. Veerasamy, W. I. Milne, C. A. Davis, S. R. P. Silva, and H. S. Mackenzie, Appl. Phys. Lett. 63, 370 (1993).

${ }^{8}$ Y. Lifshitz, G. D. Lempert, E. Grossman, I. Avigal, C. Uzan-Saguy, R. Kalish, J. Kulik, D. Marton, and J. W. Rabalais, Diamond Relat. Mater. 4, 318 (1995)

${ }^{9}$ E. Martinez, J. L. Andujar, M. C. Polo, J. Esteve, J. Robertson, and W. I. Milne, Diamond Relat. Mater. 10, 145 (2001).

${ }^{10}$ C. Casiraghi, A. C. Ferrari, R. Ohr, A. J. Flewitt, D. P. Chu, and J. Robertson, Phys. Rev. Lett. 91, 226104 (2003).

${ }^{11}$ X. Yu, X. Zhang, C. B. Wang, F. T. Liu, and Z. Q. Fu, Surf. Coat. Technol. 201, 4995 (2007).

${ }^{12}$ A. C. Ferrari, B. Kleinsorge, N. A. Morrison, A. Hart, V. Stolojan, and J. Robertson, J. Appl. Phys. 85, 7191 (1999).

${ }^{13}$ S. D. Brotherton, Semicond. Sci. Technol. 10, 721 (1995).

${ }^{14}$ A. A. D. T. Adikaari and S. R. P. Silva, J. Appl. Phys. 97, 114305 (2005).

${ }^{15}$ A. A. D. T. Adikaari, N. K. Mudugamuwa, and S. R. P. Silva, Appl. Phys. Lett. 90, 171912 (2007).

${ }^{16}$ A. C. Ferrari and J. Robertson, Phys. Rev. B 61, 14095 (2000).

${ }^{17}$ A. C. Ferrari, S. E. Rodil, and J. Robertson, Phys. Rev. B 67, 155306 (2003).

${ }^{18}$ A. C. Ferrari and J. Robertson, Phys. Rev. B 64, 075414 (2001).

${ }^{19}$ Y. Miyajima, J. M. Shannon, S. J. Henley, V. Stolojan, D. C. Cox, and S. R. P. Silva, Thin Solid Films 516, 257 (2007).

${ }^{20}$ T. V. Kononenko, V. V. Kononenko, S. M. Pimenov, E. V. Zavedeev, V. I. Konov, V. Romano, and G. Dumitru, Diamond Relat. Mater. 14, 1368 (2005). 